\title{
The Impact of Cultural Intelligence and Psychological Hardiness on Homesickness among Study Abroad Students
}

\section{J. Kline Harrison \\ Wake Forest University}

\section{Holly H. Brower \\ Wake Forest University}

Over the last decade the number of students studying abroad has increased $150 \%$ to more than a quarter of a million (Open Doors, 2008). The programs in which these students participate are no longer seen as simply a campus extension of academic exercise, but as an overall educational experience that develops holistic life skills in the participants (Berg, 2003). Through their sojourns, students develop, among other traits, global competency, defined as a tolerance for ambiguity, intellectual flexibility, and an ease of conducting affairs in multicultural contexts (Proceedings, 2007).

Because of the growth and impact of study abroad experiences, it is important to identify and evaluate factors contributing to students' success. Unfortunately, a survey of leading U.S. study abroad institutions found that $96 \%$ of assessment instruments only gauged students' satisfaction as the single measurement of success (Berg, 2003). In contrast, the literature on international job assignments identifies psychological adjustment as a vital construct underlying the success of expatriate employee experiences (Selmer \& Leung, 2003). Furthermore, personality characteristics or stable personal traits are considered among the most important factors affecting the psychological adjustment of expatriate employees, and thus their success (Huang, Chi \& Lawler, 2005; Jassawalla, Truglia, \& Garvey, 2004). Two of these traits that are especially appropriate in the study of successful cross-cultural adjustment are cultural intelligence and psychological hardiness. Below we introduce these constructs and present a rationale for predictions about their impact on successful psychological adjustment for study abroad participants.

This paper makes three important contributions to the literature. First, we examine the construct of cultural intelligence in the study abroad context. This construct has been defined and introduced in the business literature (Earley, 2002; Earley \& Ang, 2003; Earley \& Mosokowski, 2004; Tan, 
2004) but we were unable to locate discussions or tests of it in study abroad experiences. Therefore, we extend the understanding of the construct looking at its predictive power in the context of university students studying abroad. The construct has demonstrated powerful effects on the success of business leaders; therefore, broadening our knowledge about how cultural intelligence affects important student outcomes helps us understand both the construct as well as how to influence successful study abroad experiences.

Furthermore, this paper contributes to our understanding of psychological hardiness and its relationship with and impact upon these other key constructs. To date, we have not found another study that has examined the relationship between psychological hardiness and cultural intelligence. Below, we describe the proposed relationship between the two. We also extend the literature on study abroad outcomes by examining the joint impact of these pertinent variables. The extension to the study abroad literature aids our understanding about how to facilitate effective student sojourns.

Finally, this paper extends our insight into an important student outcome: psychological adjustment as measured by homesickness. Such adjustment is an indicator of the success of the study abroad experience and student development. This study adds to our understanding of the predictors and correlates of this important outcome.

\section{Cultural Intelligence}

Cultural intelligence (CQ) can be defined as the ability to adapt successfully across varied cultures. It captures an individual's capacity to gather, interpret and act upon different cues in order to function effectively across different cultures or in multicultural situations (Earley \& Ang, 2003; Tan, 2004). It is important to note that CQ is not merely cognitive understanding about cultural differences nor is it relegated to fluency in a foreign language. Rather, it consists of three dimensions including the emotional/motivational and physical in addition to the cognitive (Earley, 2002; Earley \& Mosokowski, 2004; Earley \& Peterson, 2004). Therefore, people with high cultural intelligence make sense of new and different situations related to cultural differences and they are motivated to act on the new understanding of cues that they see and experience.

These three dimensions of CQ have been described as head, heart, and body (Earley \& Mosokowski, 2004). The head refers to the cognitive knowledge about cultural differences. This knowledge can be both declarative, such as knowing when the Chinese New Year is, as well as procedural, such as understanding that relationships are important to the Chinese people and thus it is important to establish a connection before jumping into a business 
relationship (Tan, 2004). But, it is not enough to only have knowledge about cultural differences. One must also be motivated, have the desire, to adapt to a new culture and to "fit in" (Earley, 2002). This dimension is referred to as the heart of CQ (Earley \& Mosokowski, 2004). Individuals with strong emotional/motivational CQ have a strong sense of their own efficacy or ability to understand and adapt to a new culture (Earley, 2002; Earley \& Peterson, 2004). If they don't believe in their own ability, they are likely to disengage, especially after experiencing an early failure. Finally, to be considered high in $\mathrm{CQ}$, a person must actually act on their knowledge and passion. They try to mimic the habits and mannerisms of other cultures. They are able to physically adapt their behaviors to be familiar to natives.

Cultural intelligence is a relatively new construct introduced in this decade (Alon \& Higgins, 2005; Crowne, 2008; Earley \& Ang, 2003) and the empirical evidence is scant. Most of the scientific exploration has been on outcomes associated with CQ (Crowne, 2008). These outcomes include cultural judgment and decision making, cultural adaptation, task performance in culturally diverse settings (Ang et al., 2007) and leadership success abroad (Alon \& Higgins, 2005). In addition, Crowne (2008) found several important antecedents or correlates to CQ including study abroad experience, living abroad for work, and even the number of countries travelled to for vacation. Most pertinent to this particular study was the finding that prior education abroad was significantly related to total CQ and to all the individual dimensions of CQ.

Unfortunately, the design of Crowne's (2008) study could not distinguish causality in the relationship so we are unable to tell whether the culturally intelligent student tends to study abroad or whether study abroad facilitates cultural intelligence growth. Likewise, previous studies identified adaption and other specific types of abroad success as correlates with cultural intelligence but the direction of the influence is unclear (Ang et al., 2007; Early, 2002). It makes intuitive sense that students with higher cultural intelligence would have better adjustment when studying abroad, but this relationship has not been demonstrated empirically. The current study seeks to better understand these relationships. In addition, this study investigates the effect of the relationship between CQ and psychological adjustment under conditions of psychological hardiness, another construct that has demonstrated significant effects on crosscultural adjustment (Kuo \& Tsai, 1986).

\section{Psychological Hardiness}

As previously noted, personality characteristics are considered among the most important factors affecting the adjustment of expatriate employees, 
and thus their success (Huang, Chi \& Lawler, 2005; Jassawalla, Truglia, \& Garvey, 2004). Given that research on study abroad adjustment has shown parallel dimensions with those of expatriate adjustment (Robie \& Ryan, 1996), it follows that personality variables would be equally important factors impacting the cross-cultural adjustment of students. One personality variable that seemingly would impact students' adjustment to their often challenging and bewildering host cultures is psychological hardiness $(\mathrm{PH})$. Because of its influence on individuals' coping mechanisms during high stress situations and because it has been found to positively impact immigrants' adjustment to the U.S. culture (Kuo \& Tsai (1986), we would expect this variable to correspondingly influence the psychological adjustment of study abroad students.

Psychological hardiness, which evolved out of the literature on stressresiliency (Kobasa, 1979), is described as a single latent variable (Britt, Adler, $\&$ Bartone, 2001). It is believed to influence how individuals experience (or appraise) and cope with stressful life situations (Cole, Field, \& Harris, 2004). Individuals who are psychologically hardy experience activities as interesting and enjoyable, as being a matter of personal choice, and as important stimuli for learning (Maddi, 1999). Furthermore, they adopt coping strategies that are active and problem-focused compared to their less hardy counterparts who adopt more withdrawal and emotion-focused strategies (Sansome, Wieke, \& Morgan, 1999). Because of their PH, they are able to draw upon their own determination and efficacy in ambiguous situations and to see these situations as an opportunity for growth. Therefore, the personality dispositions underlying this construct are described as commitment, control, and challenge (Cole et al., 2004).

According to the literature (e.g., Sansome, Wieke \& Morgan, 1999; Kobasa, Maddi, and Kahn, 1982): Commitment is the tendency to actively involve oneself in whatever one does or encounters and to find those activities interesting and meaningful; control is the inclination to believe and act as though one is influential (rather than helpless) in the face of life's varied contingencies; and challenge is the tendency to view life changes as the norm and as opportunities for growth rather than threats to security.

With these three personality dispositions, individuals studying abroad should remain healthy and well-adjusted despite encounters with culturally diverse people, norms, and expectations that cause stress and anxiety. Their commitment should lead them to identify with and find meaning in their cross-cultural encounters; their control should enhance their self-efficacy in interpreting and managing the encounters; and their sense of challenge should enable them to view the encounters as stimulating and developmental. 
We expect both cultural intelligence and psychological hardiness to have positive effects on students' adjustment to study abroad. Before we describe specific hypothesized relationships and the joint effects of these traits, we turn to a short discussion of cross-cultural adjustment and homesickness.

\section{Cross-cultural Adjustment}

Cross-cultural adjustment is generally conceptualized as the extent to which individuals develop psychological comfort with varied aspects of their host culture (Black, 1988; Nicholson, 1984). Individuals who develop stronger levels of psychological comfort and become culturally adjusted tend to be more open to their host culture and to add new norms and behaviors to their native cultural foundations. Those who fail to achieve significant psychological comfort levels and remain maladjusted are often unable and/ or unwilling to assimilate new norms and behaviors (Peltokorpi, 2008). Consistent with recent research by Fenner \& Selmer (2008), our study focuses on psychological adjustment. As opposed to socio-cultural adjustment, which is often manifest in behaviors aimed at "fitting in" a host culture, psychological adjustment deals with subjective well-being or mood states (e.g., depression, anxiety, tension, and fatigue) that may not be readily discerned by behaviors. (Fenner \& Selmer, 2008; Selmer \& Leung, 2003). In other words, behaviors may simply reflect necessary accommodation rather than actual adjustment. Therefore, a primary challenge in expatriate success is achieving significant psychological adjustment.

Previous literature on students studying abroad has looked at crosscultural adjustment and personality variables from several perspectives. Examples include Savicki et al (2004), who investigated contrasts, changes, and correlates among study abroad students. They found clusters of personality traits (e.g., anxiety, extraversion, openness, and agreeableness) and coping strategies (e.g., active, planning, denial, and behavioral disengagement) significantly related to intercultural adjustment. Similarly, Ward and Kennedy (2007) examined the specific personality variables of extraversion and locus of control on cross-cultural adjustment and found that locus of control was a predictor of psychological adjustment. Although there are varied measures of psychological adjustment, homesickness (as defined below) is one indicator of the degree of well-being and positive mood and attitude associated with the environment in which students find themselves. It is an especially strong indicator of psychological adjustment, as opposed to behavioral adjustment.

\section{Homesickness}

As a measure of student psychological adjustment and a component of 
culture shock (Poyrazli \& Lopez, 2007), homesickness has been described as a form of separation anxiety (Brewin, Furnham \& Howes, 1989) and defined as a longing or desire for familiar environments (Van Tilburg, Vingerhoets, \& Van Heck, 1997). Fisher and Hood (1987) described it as a "complex cognitive motivational emotional state concerned with grieving for, yearning for, and being preoccupied with thoughts of home" (p. 426). It appears to be more pronounced for individuals who are anxiously attached and those who perceive themselves to be highly reliant on others (Brewin et al., 1989).

Most research in university settings has examined the effects on first year students who go away to college, with homesickness as an indicator of student adjustment and satisfaction. In fact, some sixty percent of first year college students experience homesickness (Brewin et al., 1989). The evidence shows that homesickness is associated with such outcomes as: increased cognitive failures, poor concentration, late work, and decrease in work quality (Archer et al., 1998; Brewin et al., 1989; Fisher \& Hood, 1987; Fisher, Murray \& Frazier, 1985); depression, anxiety and somatic changes (Beck, Taylor \& Robbins, 2003; Fisher \& Hood; Stroebe et al., 2002); reduced satisfaction with the current environment (Stokols et al., 1983); and loneliness, sadness and adjustment difficulties (Constantine et al., 2005; Stroebe, van Vliet, Hewston, $\&$ Willis, 2002). Summarizing these outcomes, we can say that homesickness is associated with a sense of depression and dissatisfaction, indicating at least a temporary lack of adjustment to a new context.

There is much less evidence of the effects of study abroad on feelings of homesickness than the evidence related to the effects of going away to college on homesickness. However, studies in the United States have shown that international students experience homesickness due to culture shock (Chapdelaine \& Alexitch, 2004; Poyrazli \& Lopez, 2007; Ward et al., 2001). In fact, students with the greatest cultural differences and less social interaction experienced stronger culture shock and more homesickness such that the greater the differences between the home culture and the host culture, the more homesickness (Eurelings-Bontekoe et al., 2000; Yeh \& Inose, 2003). When foreign students' home culture was most different and where they had language difficulties, they were also more likely to experience negative discrimination. This discrimination experience was also associated with more homesickness (Poyrazli \& Lopez, 2007). In addition, at least one previous study specifically examined homesickness as an indicator of psychological adjustment among study abroad students (Ward and Kennedy, 1993). They found that psychological well-being was predicted by homesickness among secondary students living abroad.

In this paper, we replicate previous research by looking at homesickness 
as an outcome that reflects student well being and psychological adjustment in the host culture. Homesickness is another indicator that students studying abroad have adapted well to the new context and are thriving. Some might argue that some degree of homesickness is natural for anyone living for an extended period of time a significant distance from family, friends, and familiarity; however, we would remind readers of the definition of homesickness adopted for this study. Such a phenomenon is not merely a fondness for familiarity and missing home and loved ones. As defined, this sense of homesickness is accompanied by depression and anxiety, negative moods and dissatisfaction. Therefore, when the missing of friends, family and familiarity reaches this level, we consider it a sign of maladjustment.

In addition, we extend our understanding of the predictors of homesickness by examining the effects of cultural intelligence and psychological hardiness on this important adjustment indicator. We expect to find a negative relationship between these student traits and homesickness. So, this study will extend our understanding of the causes and effects of student homesickness. In addition, we will better understand successful study abroad experiences by examining some of the conditions that affect homesickness in students while studying abroad.

\section{Hypotheses}

As summarized above, the literature on cultural intelligence demonstrates a strong relationship between individual CQ and cross-cultural success in international business settings (Alon \& Higgins, 2005; Ang et al., 2007; Earley \& Ang, 2003). We expect that the same holds true for students studying abroad. In fact, the definition of cultural intelligence includes a strong ability to adjust to unfamiliar cultures. For those with higher CQ, meaning that they have stronger cognitive, motivational and physical understanding of crosscultural settings, we expect to see better adaptation to a study abroad context, as indicated through less homesickness, than individuals with lower CQ.

Hypothesis 1: Individuals with high cultural intelligence will experience greater adjustment (less homesickness).

Hypothesis1a: Individuals with high cognitive cultural intelligence will experience greater adjustment (less homesickness).

Hypothesis1b: Individuals with high emotional cultural intelligence will experience greater adjustment (less homesickness).

Hypothesis1c: Individuals with high physical cultural intelligence will experience greater adjustment (less homesickness). 
In addition, as described above, we expect a positive relationship between $\mathrm{PH}$ and cross-cultural adjustment. Specifically, we anticipate that students with higher $\mathrm{PH}$ will enjoy the challenge of living and studying in a new culture. They will be more likely to interact and form friendships as they enjoy the challenge of the new environment and are committed to making the most of the opportunity. They are also more likely to view the differences between their host and home cultures positively and to embrace the opportunities to explore new things and ideas. These positive effects combined with their sense of personal control over their situation and optimistic engagement will make them more likely to enjoy the new foods, accents, formalities and other nuances of a foreign culture. They are more likely to form friendships with foreign nationals and these closer relationships are likely to reduce their homesickness and missing of family, friends and familiar settings.

Hypothesis 2: Individuals strong in psychological hardiness will experience greater adjustment (less homesickness).

Hypothesis2a: Individuals with high commitment psychological hardiness will experience greater adjustment (less homesickness).

Hypothesis2b: Individuals with high control psychological hardiness will experience greater adjustment (less homesickness).

Hypothesis2c: Individuals with high challenge psychological hardiness will experience greater adjustment (less homesickness).

In addition to these direct effects, we expect the greatest impact on crosscultural adjustment when a student has both strong CQ and strong PH. In a situation where a student has high CQ but is not psychologically hardy, they may have the understanding and behavioral intentions to be successful in a new culture; however, they may not have the ability to capitalize on that understanding or the good intentions. Being low in $\mathrm{PH}$ would indicate that a student may not have the commitment to push her or himself out to fully experience the host culture. They may have the intentions but not have the drive to challenge themselves to form relationships with host nationals and to believe that they have a degree of control over the extent to which they engage in the host culture.

By the same token, a student who is considered psychologically hardy but does not have strong CQ will not experience the most successful crosscultural adjustment. They may demonstrate commitment and control and embrace challenge in familiar settings, but these qualities may be overwhelmed when they do not understand the setting and are not motivated to embrace 
the new culture. Cultural intelligence gives individuals the confidence and understanding of the context to capitalize on their personalities' tendency toward commitment, control and challenge.

Therefore, we expect the strongest adjustment to occur when a student is strong in both cultural intelligence and psychological hardiness. Adjusting to a new culture is broader than merely understanding and appreciating it. When combined with a hardy personality, a person can thrive in the new setting.

Hypothesis 3: Individuals with both strong cultural intelligence and psychological hardiness will experience more adjustment (less homesickness) than individuals high on only one or neither dimension.

\section{Method}

\section{Respondents}

This study was conducted among undergraduate study abroad students from a small, private university in the southeastern United States. A sample of 537 students was surveyed via e-mail, with 188 receiving a web-based questionnaire during a spring semester abroad and another 349 receiving the same questionnaire while studying abroad during a fall semester. Approximately two weeks after the initial email, a follow-up e-mail was sent asking nonrespondents for their cooperation in completing the questionnaire. Ninety-five valid surveys were ultimately returned for an $18 \%$ response rate. Although this response rate was lower than anticipated, it was not inconsistent with other web-based survey results. Twenty-five percent of the papers reviewed by Manfreda, Bosnjak, Berzelak, Hass, and Vehovar (2006) in their meta-analysis comparing web surveys to other survey modes had an equivalent or lower response rate than ours.

Regarding the background of respondents, 20 were males and 76 were females. Twenty-two percent of the total group were in their sophomore year of study, 75 percent in their junior year, and two percent in their senior year. While only 25 percent of the respondents had lived abroad previously, 90 percent had traveled internationally before their study abroad experience. Thirty-one percent had lived in an urban setting the majority of their life, with $61 \%$ coming from a small town, and $8 \%$ from rural areas.

\section{Measures}

The questionnaire used in this study consisted of widely recognized standardized instruments with high reliabilities to assess the independent variables of cultural intelligence and psychological hardiness, as well as the 
dependent variable of homesickness. Surveys were administered at two points in time where independent variables were collected at the very beginning of the study abroad experience and the dependent variable was collected in a second wave 13-14 weeks later, near the end of the sojourn. This timing for assessing homesickness served to mitigate concerns that it was an early adjustment issue. In this case, students were asked about their degree of adjustment after nearly a full semester and just two to three weeks from the time when they would return to their homes. For both data collections, an email was sent to students asking them to participate that included a link to an electronic survey. A reminder invitation was sent approximately two weeks later.

To assess cultural intelligence, we used a 12-item measure developed by Early and Mosokowski (2004) that taps into the three dimensions of cultural intelligence: cognitive, physical, and emotional using a 5-point Likert scale. We conducted reliability analyses on these items and found acceptable $(\alpha$ $>.70)$ internal reliabilities for a single composite measure $(\alpha=.78)$ and for each of the theorized dimensions of physical $(\alpha=.75)$, and emotional $(\alpha=.81)$. The Cronbach alpha for the cognitive dimension was lower than expected $(\alpha=.60)$; however, benchmarks (i.e., rules of thumb) for judging the adequacy of reliability coefficients, have historically ranged from .50 to .90 (Helms, Henze, Sass \& Mifsud, 2006).

Psychological hardiness was measured using the short form developed by Bartone (1989) with a 5-point Likert scale. As expected, the 30 items yielded high internal reliability of .73. Consistent with the cultural intelligence measure, subsequent reliability analysis was performed on the three theorized dimensions of commitment, control, and challenge which yielded an alpha coefficient of .70, .58, and .75, respectively. Although the Cronbach alpha for the dimension of control was lower than expected, it did fall within the historical range of benchmarks for reliability coefficients (Helms et. al., 2006).

For homesickness, we used the 25-item Dundee Relocation Inventory (questionnaire F) which measures the intensity of homesickness in response to a residential transition (see Fisher and Hood, 1987; Fisher, 1988). This scale has been used and validated in several studies (e.g. Burt, Strongman \& Costanzo, 1998; Fisher \& Hood, 1987, 1988; Kazantziss \& Flett, 1988; Smreek \& Stiksrud, 1994). Participants were asked to rate how often they had experienced the feeling described in each item in the last three weeks on a three-category rating scale from 0 (never) to 2 (often). Reliability analysis yielded a highly acceptable alpha coefficient of .94.

\section{Results}

Table 1 shows the correlations and scale reliabilities of all variables 
used in this study. One-tailed analysis of bivariate correlations between the study variables indicated support for all hypotheses. Hypothesis 1 stated that CQ would be negatively related to homesickness. Using our measure of homesickness, higher scores indicate better adjustment (less homesickness); therefore, the stronger positive correlations indicate negative relationships (i.e., a positive correlation between CQ and homesickness would indicate that as CQ increases, adjustment increases as indicated by less homesickness). The correlation between overall CQ and homesickness was significantly positive at $\mathrm{r}=.452(\mathrm{p}<.001)$. In addition, all three components of CQ, cognitive, emotional, and physical, were significant at .246 (p<.05), .380 ( $<<.001)$ and $.341(\mathrm{p}<.001)$, respectively.

We conducted further analysis using a median split procedure consistent with prior cross-cultural research (e.g., Black, 1990, Harrison et al., 1996; Harrison \& Voelker, 2008). Scores on the composite measure of cultural intelligence as well as its three dimensions were categorized as "high" if they were above the median on each scale and those below the median were categorized as "low." One-way ANOVA results supported the first hypothesis (see Table 2). Those with high CQ $(x=2.60$, s.d. $=0.26)$ were significantly different from those with lower CQ $(\mathrm{x}=2.33$, s.d. $=0.38)$ on homesickness $(\mathrm{F}[1,78]=12.31, \mathrm{p}=.001)$. In addition, analysis of the three dimensions of CQ also yielded support for Hypotheses 1a - c. Those classified as high on cognitive CQ $(\mathrm{x}=2.54$, s.d. $=0.32)$ were significantly different from those lower on cognitive CQ $(\mathrm{x}=2.38$, s.d. $=0.39)$ on homesickness $(\mathrm{F}[1,89]=$ $4.89, \mathrm{p}=.03)$. Those classified as high on emotional CQ $(\mathrm{x}=2.56$, s.d. $=0.26)$ were significantly different from those classified as low on emotional CQ $(\mathrm{x}=$ 2.32 , s.d. $=0.44)$ on homesickness $(F[1,87]=10.11, \mathrm{p}=.002)$. Finally, those classified as high on physical CQ $(\mathrm{x}=2.55$, s.d. $=0.33)$ were significantly different from those classified as low on physical CQ $(x=2.35$, s.d. $=0.39)$ on homesickness $(\mathrm{F}[1,89]=7.11, \mathrm{p}=.009)$.

The second set of analyses tested the relationship between PH and students' expressions of homesickness while abroad. Hypothesis 2 stated that students who were more psychologically hardy would experience less homesickness. Again, one-tailed analyses of the bivariate correlations generally supported this hypothesis, except for one of the components of psychological hardiness. The correlation between overall $\mathrm{PH}$ and homesickness was significantly positive $(\mathrm{r}=.33, \mathrm{p}<.001)$. Analyses of the subcomponents of $\mathrm{PH}$ found that only one, control, was not significantly associated with homesickness $(\mathrm{r}=.10, \mathrm{p}<.180)$. The correlations with the other two dimensions were significant: commitment $(\mathrm{r}=.21, \mathrm{p}<.05)$ and challenge $(\mathrm{r}=.36, \mathrm{p}<.001)$. See Table 1 .

Again, the same median split procedure described above was performed 
where scores on $\mathrm{PH}$ and its three components that fell above the median were classified as "high" and those that fell below the median were classified as "low." One-way ANOVA results demonstrated support for Hypothesis 2 (see Table 3). Those with high overall PH $(\mathrm{x}=2.54$, s.d. $=0.25)$ were significantly different from those with low overall $\mathrm{PH}(\mathrm{x}=2.38$, s.d. $=0.45)$ on homesickness $(F[1,78]=4.12, \mathrm{p}=.046)$. Only one of the three dimensions, challenge, demonstrated support for this hypothesis. Those with high $\mathrm{PH}$ challenge $(\mathrm{x}=2.57$, s.d. $=0.24)$ were significantly different from those with low PH-challenge $(\mathrm{x}=2.36$, s.d. $=0.44)$ on homesickness $(\mathrm{F}[1,76]=6.96$, $\mathrm{p}$ $=.01$ ). Analysis of the other two dimensions of $\mathrm{PH}$ did not find a difference between high and low scores on their experiences of homesickness. Therefore, only Hypothesis $2 \mathrm{c}$ was supported.

The third hypothesis examined the combined effects of cultural intelligence and psychological hardiness on homesickness. To test this effect, subjects were divided into three groups based on their classification as high or low on CQ and on PH. Those below the median on both measures were designated as the low group. If subjects were below the median on one measure but above the median on the other, they were designated as the mixed group. Those above the median on both measures were designated as the high group. One-way ANOVA was then conducted for each possible pairing of groups (i.e., the low and mixed groups, the mixed and high groups, and the low and high groups were all compared with each other). See Table 4. Results indicated no significant difference between the low group $(\mathrm{x}=2.28$, s.d. $=0.44)$ and the mixed group $(\mathrm{x}=2.46$, s.d. $=0.31)$ on homesickness $(\mathrm{F}[1,44]=2.50$, ns). However, the high group $(\mathrm{x}=2.62$, s.d. $=0.20)$ was significantly different from both the low group $(\mathrm{F}[1,46]=11.43, \mathrm{p}=.001)$ and the mixed group $(\mathrm{F}[1,42]$ $=3.99, \mathrm{p}=.05)$. See Table 4 . Therefore, hypothesis 3 was supported.

\section{Discussion}

Each of the three hypotheses received support from these analyses. More specifically, this study demonstrated that students who have strong cultural intelligence before their sojourn were more apt to adjust to the cross cultural context, experiencing less homesickness while abroad. Of the three dimensions of CQ -- cognitive, emotional, and physical-- emotional CQ had the strongest relationship with psychological adjustment. Given the "head, heart, and body" analogy about CQ (Earley \& Mosokowski, 2004), these results suggest that cultivating the "heart" is most powerful. Study abroad programs, parents, and students should emphasize the development of empathy and passion for culture. That is not to suggest that emphasis on language development and cognitive understanding of cultural differences, as well as coping and adaptive 
skills, are not important. All three CQ dimensions significantly predicted psychological adjustment; however, the heart demonstrated the strongest ability to predict homesickness.

The tests for the relationship between $\mathrm{PH}$ and homesickness were less clear cut. Correlation analysis demonstrated a strong positive relationship between $\mathrm{PH}$ and psychological adjustment, as predicted, but the control dimension of PH was not related to homesickness. The strongest correlation was found between the challenge dimension of PH and homesickness. Furthermore, using the median split procedure, only the challenge dimension of $\mathrm{PH}$ significantly predicted psychological adjustment. Given this dimension represents one's view of change as an opportunity for growth rather than a threat to personal security (Sansome, Wieke \& Morgan, 1999; Kobasa, Maddi, and Kahn, 1982), it makes sense that those who are strong in the challenge dimension struggle less with distance from the safety and security of home. We would expect them to approach their study abroad sojourn as an exciting opportunity for new discoveries rather than regretting what they might be missing in their home environment.

The control dimension of $\mathrm{PH}$ is similar to internal locus of control in that it assumes a sense of control over one's life and environment. This dimension was not associated with homesickness. This result is both positive and reasonable. It is positive because it demonstrates divergent validity of the construct in that not all dimensions of $\mathrm{PH}$ were positively related to homesickness. Further, it is reasonable to conclude that studying abroad may enable students to realize how big the world is and how relatively little control they have on their environment. Thus, their (in)ability to control their environment did not predict how much they would experience homesickness.

Finally, the commitment dimension of $\mathrm{PH}$ was correlated with homesickness, but did not indicate a relationship using the median split procedure. So, whether or not students embraced the new culture and actively involved themselves in it did not impact their degree of psychological adjustment.

The tests of the third hypothesis were especially interesting because there was no difference between having low measures of both CQ and $\mathrm{PH}$ and being strong in only one of these. Thus, if you are low in one of these, that weakness will overwhelm the strength of the other. The impact of either CQ or PH is significant only in the presence of each other. They work together to create someone who better adjusts to the cross cultural environment.

\section{Implications}

In addition to the theoretical implications already discussed, this study 
has several implications for the selection and pre-departure development of students to better ensure successful study aboard experiences. Specifically, administrators, faculty and parents should assess students on these traits prior to departure. Careful consideration should be given when a student is low in one or both of these dimensions. Perhaps targeted mentoring/counseling would facilitate better adjustment for students who are low on either trait. Programs may consider delaying departure until substantive development of psychological hardiness or cultural intelligence is achieved. Another strategy may be to target at-risk students when they go abroad and provide enhanced counseling about coping strategies and support during their sojourn.

Some universities are developing pre-departure courses for students preparing to study abroad. This study lends support to these programs, especially if they demonstrate the ability to enhance CQ and PH. Pre- and post- measures of these traits should be taken to provide empirical support that the programs are effective at developing $\mathrm{PH}$ and $\mathrm{CQ}$, thus enhancing psychological adjustment while abroad.

\section{Limitations and Future Directions}

One of the several strengths of this study is that it represents the first examination of cultural intelligence and psychological hardiness as predictors of homesickness for students studying abroad. Using homesickness as an indicator of psychological adjustment enhances our understanding about successful adjustment abroad beyond other measures of adjustment found in the literature which have tapped into differing characteristics of cross-cultural adjustment. Increased homesickness indicates that students are unable to embrace the new culture and make the most of the experience because they are restricted by a level of depression and isolation in their inability to feel secure in the new environment.

Methodologically, this study had several strengths such as the independent and dependent variables being collected at two different points in time, more than three months apart. Thus, common method biases that shed doubt on earlier published results were diminished. In addition, the data was longitudinal in that it followed students through their sojourn, collecting survey information at the very beginning of their experience and again at the end. In addition, data was collected over three semesters so that confounds related to external social, political and economic issues were marginalized compared to studies that collect data at one point in history. A final strength is that we examined students across multiple abroad settings from English-speaking locations with other students from the same university, to settings where speaking in a foreign language was necessary even though coursework occurred in English, 
to locations of deep immersion where students lived with host families in a foreign setting and functioned primarily in a language other than English. We examined whether these different types of abroad settings impacted any of the study variables and did not find any significant relationships. Nevertheless, the study design allowed us to eliminate concerns that homesickness was affected by parameters of the program rather than the characteristics of the students.

There were also two limitations to this study. The first concerns restriction of range with the survey data (Bertrand \& Mullainathan, 2001). The depth of the results could have been enhanced through other data collection methods such as interviews and other qualitative methods. We only had a single outcome measure, homesickness, which limits that breadth of the results. We would expect other outcomes measures such as satisfaction, commitment, and other indicators of adjustment to be related to CQ and PH. These and other variables should be explored in future research. The second limitation concerns the response rate. Though the percentage of valid returns was within the bounds of previous research, we were disappointed with an $18 \%$ response rate. To be considered in this sample, both time one and time two surveys had to be completed. This design led to fewer returns which may be improved with different study designs in future research.

Future research should also examine the relationships between interventions such as pre-departure courses that seek to develop cultural intelligence and psychological hardiness and to facilitate psychological adjustment abroad. Other interventions such as mentoring, counseling, and special support for high-risk students also should be examined for their impact on adjustment. Furthermore, it would be interesting to extend this research to international students studying in the U.S. Lastly, universities are not the only constituents interested in successful psychological adjustment to cross-cultural experiences. With the increased presence of business people working abroad, it would be interesting and informative to extend this research to expatriates employees.

\section{Conclusion}

This study clearly makes a contribution to the study abroad literature as well as to the body of knowledge about cultural intelligence and psychological hardiness. The results demonstrate strong predictive ability of these personality variables on students' psychological adjustment while living and studying in a foreign culture. Implications include a number of interventions that are important for study abroad administrators, parents, faculty, and students themselves to consider. 


\section{References}

Alon, I., \& Higgins, J. M. (2005). Global leadership success through emotional and cultural intelligences. Business Horizons, 48(6), 501-512. Ang, S., Dyne, L. V., Koh, C., Ng, K. Y., Templer, K. J., Tay, C., \& Chandrasekar, N. A. (2007). Cultural intelligence: Its measurement and effects on cultural judgment and decision making, cultural adaptation and task performance. Management and Organization Review, 3(3), 335-371.

Archer, J., Ireland, J., Amos, S., Broad, H., \& Currid, L. (1998). Derivation of a homesickness scale. British Journal of Psychology, 89, 205-221.

Bartone, P. (1999). Hardiness Protects Against War-Related Stress in Army Reserve Forces. Consulting Psychology Journal: Practice and Research, 51(2), 72-82.

Beck, R., Taylor, C. \& Robbins, M. (2003). Missing home: Sociotropy and autonomy and their relationship to psychological distress and homesickness in college freshmen. Anxiety, Stress, and Coping, 16, 155166.

Bertrand, M. \& Mullainathan, S. (2001). Do People Mean What They Say? Implications for Subjective Survey Data. The American Economic Review, $91(2), 67-72$.

Black, J.S. (1988). Work role transitions: A study of American expatriate managers in Japan. Journal of International Business Studies, 9, 277-294.

Black, J.S., \& Gregersen, H.B. (1991). The other half of the picture: Antecedents of spouse cross-cultural adjustment. Journal of International Business Studies, 22, 461-477.

Black, J.S., Mendenhall, M., \& Oddou, G. (1991). Toward a comprehensive model of international adjustment: An integration of multiple theoretical perspectives. Academy of Management Review, 16, 291-317.

Black, J.S. \& Stephens, G. (1989). The Influence of the Spouse on American Expatriate Adjustment and Intent to Stay in Pacific Rim Overseas Assignments. Journal of Management, 15(4), 529-544.

Brewin, C. R., Furnham, A. \& Howes, M. (1989). Demographic and psychological determinants of homesickness and confiding among students. British Journal of Psychology, 80, 467-477.

Chapdelaine, R. F., \& Alexitch, L. R. (2004). Social skills difficulty: Model of culture shock for international graduate students. Journal of College Student Development, 45, 167-184.

Cole, M., Field, H. \& Harris, S. (2004). Student Learning Motivation and Psychological Hardiness: Interactive Effects on Students' Reactions to a Management Class. Academy of Management Learning and Education, 


\section{3(1), 64-85.}

Constantine, M. G., Anderson, G. M., Berkel, L. A., Caldwell, L.D., \& Utsey, S. O. (2005). Examining the cultural adjustment experiences of African international college students: A qualitative analysis. Journal of Counseling Psychology, 52, 57-66.

Crowne, K.A. (2008). What leads to cultural intelligence? Business Horizons, 51, 391-399.

Earley, P. C. (2002). Redefining interactions across cultures and organizations: Moving forward with cultural intelligence. In B. M. Staw \& R. I Sutton (Eds.), Research in organizational behavior (pp. 271299). New York: JAI Press.

Earley, P. C. \& Ang, S. (2003). Cultural intelligence: Individual interactions across cultures. Palo Alto, CA: Stanford University Press.

Earley, P. C. \& Mosakowski (2004). Cultural intelligence. Harvard Business Review, 139-146.

Earley, P. C. \& Peterson, R. S. (2004). The elusive cultural chameleon: Cultural intelligence as a new approach to intercultural training for the global manager. Academy of Management Learning and Education, 3(1), 100- 115 .

Eurelings-Bontekoe, E. H., Brouwers, E. P. M., \& Verschuur, M. J. (2000). Homesickness among foreign employees of a multinational high-tech company in the Netherlands. Environment and Behavior, 32, 443-456.

Fenner, C, R., Jr. \& Selmer, J. (2008). Public sector expatriate managers: psychological adjustment, personal characteristics and job factors. The International Journal of Human Resource Management. 19(7), 12371252.

Fisher, S. \& Hood, B. (1988). Vulnerability factors in the transition to university: Self-reported mobility history and sex differences as factors in psychological disturbance. British Journal of Psychology, 79, 309-320.

Fisher, S. \& Hood, B. (1987). The stress of the transition to university: A longitudinal study of psychological disturbance and vulnerability to homesickness. British Journal of Psychology, 78, 425-442.

Fisher, S., Murray, K., \& Frazer, N. (1985). Homesickness, health and efficiency in first year students. Journal of Environmental Psychology, 5, 181-195.

Harrison, J. Kline, Chadwick, Margaret, \& Scales, Maria (1996). The Relationship between Cross-Cultural Adjustment and the Personality Variables of Self-Efficacy and Self-Monitoring. International Journal of Intercultural Relations, 20(2), 167-188. 
Harrison, K. \& Voelker, E. (2008). Two Personality Variables and the Crosscultural Adjustment of Study Abroad Students. Frontiers, 17.

Helms, J.E., Henze, K.T., Sass, T.L., \& Mifsud, V.A. (2006). Treating Cronbach's Alpha Reliability Coefficients as Data in Counseling Research. The Counseling Psychologist, 34(5), 630-660.

Kobasa, S., Maddi, S. \& Kahn, S. (1982). Hardiness and Health: A Prospective Study. Journal of Personality and Social Psychology, 42(1), 168-177.

Kuo, W.H., \& Tsai, Y. (1986). Social Networking, Hardiness and Immigrant's Mental Health. Journal of Health and Social Behavior, 27(June), 133-149.

Maddi, S. (1999). The Personality Construct of Hardiness: I. Effects on Experiencing, Coping, and Strain. Consulting Psychology Journal: Practice and Research, 51(2), 83-94.

Manfreda, K.L., Bosnjak, M., Berzelak, J., Haas, I., \& Vehovar, V. (2006).

Web surveys versus other survey modes. International Journal of Market Research, 50(1), 79-104.

Nicholson, N. (1984). A theory of work role transitions. Administrative Science Quarterly, 29, 172-191.

Open Doors 2008: U.S. Students Studying Abroad (2008, November 17). Institute for International Education Network.

Peltokorpi, V. (2008). Cross-cultural adjustment of expatriates in Japan. The International Journal of Human Resource Management, 19 (9), 15881606.

Poyrazli, S. \& Lopez, M. D. (2007). An Exploratory Study of Perceived

Discrimination and Homesickness: A Comparison of International Students and American Students. The Journal of Psychology, 141(3), 263-280.

Poyrazli, S. \& Lopez, M. D. (2007). Proceedings of the Forum on Study Abroad and Economic Competitiveness (Washington D.C.: National Press Club, 2007).

Robie, Chet, \& Ryan, Ann Marie (1996). Structural Equivalence of a Measure of Cross-Cultural Adjustment. Educational and Psychological Measurement, 56(3), 514-521.

Sansone, D., Wiebe, D., \& Morgan, C. (1999). Self-regulating Interest:

The Moderating Role of Hardiness and Conscientiousness. Journal of Personality, 67(4), 701-733.

Selmer, J., \& Leung, A.S.M. (2003). International adjustment of female vs male business expatriates. International Journal of Human Resource Management, 14(7), 1117-1131. 
Stokols, D., Schumaker, S. A. \& Martinez, J. (1983). Residential mobility and personal well being. Journal of Environmental Psychology, 3, 5-19.

Stroebe, M., vanVliet, T., Hewstone, M., \& Willis, H. (2002). Homesickness among students in two cultures: Antecedents and consequences. British Journal of Psychology, 93, 147-168.

Tan, J. (2004). Cultural intelligence and the global economy. Issues and Observations, 24(5), $19-21$.

Van Tilburg, M. A. L., Vingerhoets, J. J. M., Van Heck, G. L. (1997).

Coping with homesickness: The construction of the adult homesickness coping questionnaire. Journal of Personality and Individual Differences, 22, 901-907.

Vande Berg, Michael (2003). The Case for Assessing Educational Outcomes in Study Abroad. Advances in International Marketing, 13, 23-36.

Ward, C. \& Kennedy, A. (1993). Psychological and socio-cultural adjustment during cross-cultural transitions: A comparison of secondary students overseas and at home. International Journal of Psychology, 28, 129 - 147.

Ward, C., Bochner, S., \& Furnham, A. (2001). The psychology of culture shock (2nd ed.). Philadelphia: Routledge. 


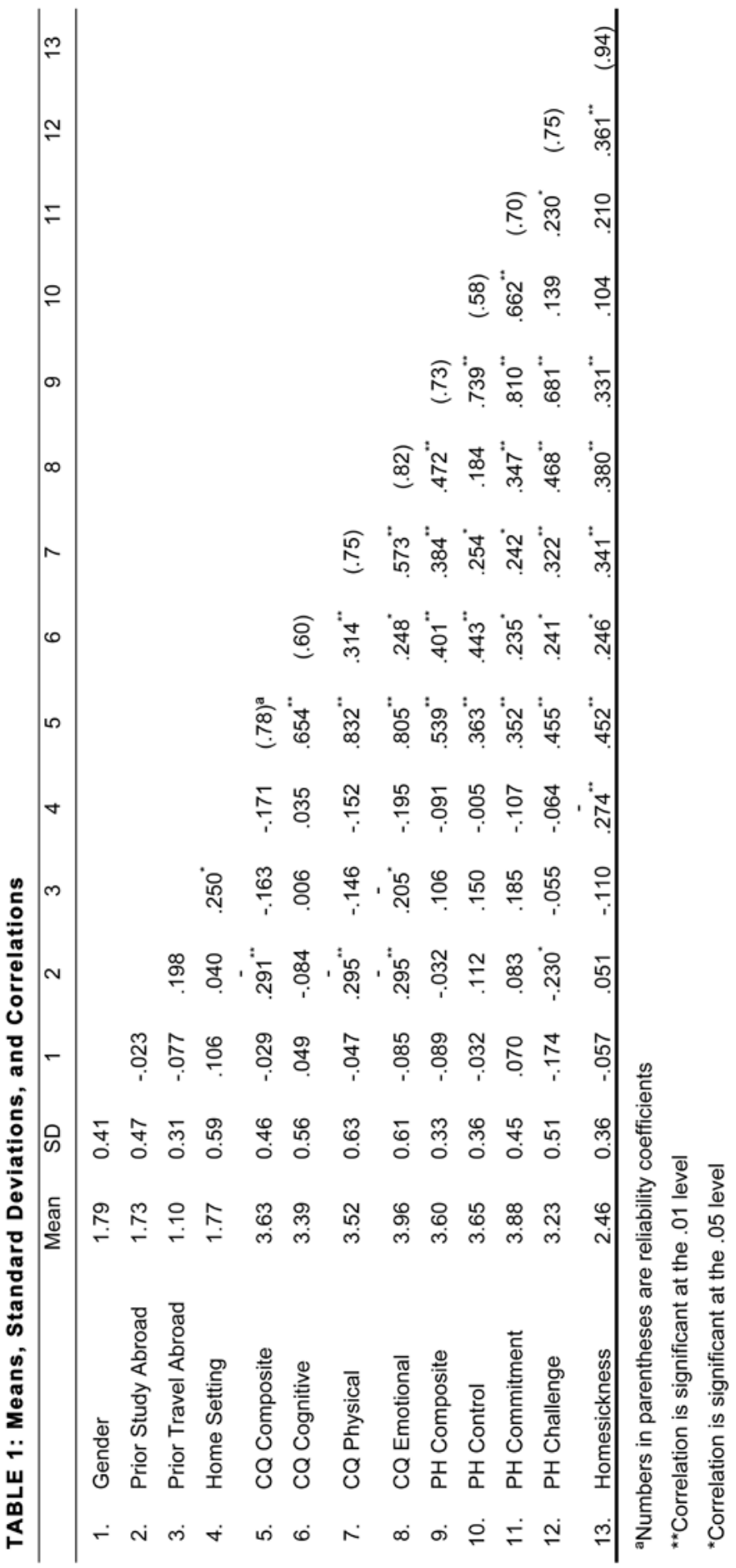


Frontiers: The Interdisciplinary Journal of Study Abroad

Table 2: Means and Standard Deviations of Median Splits for Intelligence

\begin{tabular}{|c|c|c|c|}
\hline & High Composite & Low Composite & $\mathrm{F}$ \\
\hline Homesickness & & & \\
\hline $\bar{x}$ & 2.60 & 2.33 & $12.31^{* *}$ \\
\hline \multirow[t]{2}{*}{ sd } & 0.26 & 0.38 & \\
\hline & High Cognitive & Low Cognitive & $\mathrm{F}$ \\
\hline $\bar{x}$ & 2.54 & 2.38 & $4.89^{\star}$ \\
\hline \multirow{2}{*}{ sd } & 0.32 & 0.39 & \\
\hline & High Emotional & Low Emotional & $\mathrm{F}$ \\
\hline $\bar{x}$ & 2.56 & 2.32 & $10.11^{\star \star *}$ \\
\hline \multirow[t]{2}{*}{ sd } & 0.26 & 0.44 & \\
\hline & High Physical & Low Physical & $\mathrm{F}$ \\
\hline $\bar{x}$ & 2.55 & 2.35 & $7.11^{\star \star}$ \\
\hline sd & 0.33 & 0.39 & \\
\hline
\end{tabular}

** Significant at the 0.01 level (1-tailed)

* Significant at the 0.05 level (1-tailed)

Table 3: Means and Standard Deviations of Median Splits for Hardiness

\begin{tabular}{|c|c|c|c|}
\hline & High Composite & Low Composite & $\mathrm{F}$ \\
\hline Homesickness & \multirow{3}{*}{$\begin{array}{l}2.54 \\
0.25 \\
\end{array}$} & \multirow{3}{*}{$\begin{array}{l}2.38 \\
0.45\end{array}$} & \multirow{3}{*}{$4.12^{*}$} \\
\hline $\bar{x}$ & & & \\
\hline \multirow[t]{2}{*}{ sd } & & & \\
\hline & High Commitment & Low Commitment & $\mathrm{F}$ \\
\hline $\bar{x}$ & 2.52 & 2.42 & 1.24 \\
\hline \multirow[t]{2}{*}{ sd } & 0.30 & 0.41 & \\
\hline & High Control & Low Control & $\mathrm{F}$ \\
\hline$\overline{\mathrm{x}}$ & 2.49 & 2.44 & 0.25 \\
\hline \multirow[t]{2}{*}{ sd } & 0.34 & 0.40 & \\
\hline & High Challenge & Low Challenge & $\mathrm{F}$ \\
\hline$\overline{\mathrm{x}}$ & 2.57 & 2.36 & $6.96^{* *}$ \\
\hline sd & 0.24 & 0.44 & \\
\hline
\end{tabular}

*^ Significant at the 0.01 level (1-tailed)

* Significant at the 0.05 level (1-tailed) 
J. Kline Harrison and Holly Brower

Table 4: Means \& Standard Deviations of Comparative Groups for Cultural Intelligence and Psychological Hardiness

\begin{tabular}{|c|c|c|c|}
\hline & Low Group & Mixed Group & $\mathrm{F}$ \\
\hline Homesickness & & & \\
\hline$\overline{\mathrm{x}}$ & 2.28 & 2.46 & 2.50 \\
\hline \multirow[t]{2}{*}{ sd } & 0.44 & 0.31 & \\
\hline & Low Group & High Group & $\mathrm{F}$ \\
\hline$\overline{\mathrm{x}}$ & 2.28 & 2.62 & $11.43^{\star *}$ \\
\hline \multirow[t]{2}{*}{ sd } & 0.44 & 0.20 & \\
\hline & Mixed Group & High Group & $\mathrm{F}$ \\
\hline$\overline{\mathrm{x}}$ & 2.46 & 2.62 & $3.99^{\star}$ \\
\hline sd & 0.31 & 0.20 & \\
\hline
\end{tabular}

** Significant at the 0.01 level (1-tailed)

* Significant at the 0.05 level (1-tailed) 